\title{
Los sindicatos en la Argentina kirchnerista: entre la herencia de los 90 y la emergencia de un nuevo sindicalismo de base
}

\author{
Paula Varela \\ (UBA, CONICET, IPS)
}

El nuevo protagonismo sindical en la Argentina actual es un hecho ineludible. Y el impacto que esto ha tenido en las ciencias sociales académicas, también. No es para menos, el movimiento obrero "retorna" luego de tres décadas de tesis sobre el fin de la clase obrera o, en sus versiones más optimistas, de su secundarización a manos de nuevos sujetos. Si bien la propia realidad no ha alcanzado para una revisión crítica de dichas tesis, sí ha logrado abrir una serie de debates sobre las causas del "retorno sindical" en los que se ha impuesto una mirada "estatalista". Tributaria de una perspectiva de tipo institucionalista o neo-institucionalista (Etchemendy, 2012; Etchemendy y Collier, 2007) o, en otras ocasiones, más apegada a perspectivas de tipo descriptivas (Novick, 2006; Palomino y Trajtemberg, 2007; Palomino, 2008), la mirada estatalista atribuye dicho protagonismo sindical a la politica gubernamental de implantación de un "nuevo modelo de relaciones laborales" que revertiria el modelo neoliberal. Este argumento trae aparejado, las más de las veces, una evaluación positiva del "modelo sindical" en nuestro país (es decir, el modelo peronista) en la medida en que éste habría permitido conservar los resortes institucionales necesarios para su nueva puesta en funcionamiento a partir de 2003. Consideramos que este tipo de trabajos presentan un punto de partida que termina constituyéndose en un obstáculo epistemológico a la hora de analizar el nuevo protagonismo sindical: la consideración de la institución sindical como una unidad homogénea. De allí se desprenden dos tipos de problemas. El primero es que impide situar los elementos institucionales en relación con la lucha de clases, e invisibiliza un ámbito de acción, organización y lucha sindical particularmente importante en nuestro país: el de las comisiones internas y cuerpos de delegados en el lugar de trabajo. El segundo es que coloca la discusión en términos de una polarización entre "lo nuevo" y "lo viejo", oscureciendo el análisis de los rasgos de continuidad y de ruptura que el nuevo protagonismo sindical presenta respecto de la década del 90 y de las jornadas de diciembre de 2001. 
En este artículo presentaremos tres hipótesis que debaten con estas interpretaciones. La primera, que el fortalecimiento estatal de los sindicatos se enfrenta, desde el origen, a una contradicción constituyente del denominado "modelo kirchnerista": la fuerte recomposición social y gremial de la clase obrera de 2003 en adelante se despliega sobre la reproducción de las condiciones de explotación de los 90. La segunda, que esta contradicción es la base objetiva (aunque no suficiente) sobre la que se desarrolla el fenómeno del sindicalismo de base, motivo por el cual su análisis es parte central del análisis de los sindicatos postconvertibilidad. La tercera, que la presencia de una nueva generación de trabajadores ("generación 2001") en combinación con la presencia de la izquierda radical (básicamente de tradición trotskista) en el movimiento obrero, otorgan a dicho sindicalismo de base características diferenciales respecto de otros períodos de la historia del movimiento obrero en nuestro país.

\section{Contradicciones de un retorno}

Es imposible explicar el actual protagonismo sindical sin analizar las políticas llevadas adelante por el gobierno kirchnerista que le dieron aliento. Más aún, es justamente en las características específicas del fortalecimiento de los sindicatos "por arriba", que se despliega una de las claves explicativas del fortalecimiento "por abajo", es decir, del sindicalismo de base.

Uno de los pilares de la politica sindical del gobierno kirchnerista ha sido una relegitimación de las organizaciones sindicales como parte necesaria del régimen político post-convertibilidad. ${ }^{1}$ Esta relegitimación institucional se llevó adelante a través de lo que podríamos resumir bajo la fórmula "paritarias + topes salariales", es decir, la combinación entre la restitución del ámbito de negociación colectiva (debilitado al extremo durante el menemismo) y un fuerte arbitraje gubernamental directo a través de instancias (más o menos formalizadas) de "pacto social", como el Consejo del Salario o los topes de aumento salarial acordados directamente con las direcciones sindicales oficialistas. A diferencia de lo que sostienen los autores "estatalistas", que sólo destacan la restitución del ámbito de negociación colectiva, lo que observamos es que esta restitución opera combinada y limitada por un fuerte arbitraje presidencial directo que asume distintas formas durante el periodo. Observar la dinámica entre negociación colectiva y arbitraje gubernamental directo resulta fundamental para entender las tensiones de esta restauración

1. No lo analizaremos en este trabajo, pero esta política se combinó con el aliento estatal a la profundización del "modelo" de sindicalismo empresario de los 90. 
y para explicar el "giro antisindical" del gobierno de Cristina Fernández desde 2011 hasta el presente.

\section{Restauración presidencial}

En el inicio, incluso antes de la asunción de Néstor Kirchner (bajo el gobierno de Eduardo Duhalde), el arbitraje gubernamental directo rigió las relaciones laborales adoptando distintas formas y grados dictados por la necesidad de regular el salario pero también de regular el fortalecimiento sindical. De 2002 hasta 2004 el poder ejecutivo otorgó aumentos salariales de suma fija por decreto, arbitrando directamente entre capital y trabajo. Los aumentos de suma fija no remunerativos ${ }^{2}$ propiciaron una mínima recuperación de la capacidad adquisitiva del salario que había caído en términos reales en un porcentaje de más del $30 \%$ con la devaluación. A mediados de 2003, el gobierno de Kirchner propicia la primera instancia de "pacto social" a través de la regulación del Salario Mínimo Vital y Móvil (SMVM) cuyo monto se había mantenido congelado en $\$ 200$ desde 1993. El aumento otorgado es de $\$ 50$, llevando el SMVM a $\$ 250$, monto inferior al salario promedio incluso en los trabajadores no registrados. Es interesante observar que esta política de arbitraje directo por parte del ejecutivo está relacionada con lo que podriamos denominar el "clima de incertidumbre" que el "modelo kirchnerista" aún generaba en el empresariado, motivo por el cual aparecía como una variable de "riesgo" librar las relaciones entre capital y trabajo a las negociaciones colectivas, aunque más no fuera en manos de la misma dirigencia sindical de los 90. Contra todo discurso de "un antes y un después de mayo de 2003", en este primer período se continúan las políticas signadas en 2002, como garantía estatal directa de la fuerte transferencia de recursos del trabajo hacia el capital que significó la salida de la convertibilidad.

\section{La relegitimación}

El año 2004 marca el inicio del cambio de política del gobierno nacional respecto a los sindicatos, dando comienzo a la estrategia de relegitimación de las organizaciones sindicales a través, principalmente, de la figura de Hugo Moyano y la CGT. Este cambio encuentra su explicación en dos fenómenos: la consolidación del fuerte crecimiento

2. A mediados de 2003, por Decreto 392/03, se estableció que las sumas no remunerativas otorgadas serían incorporadas al básico mediante negociación colectiva posterior. 
económico (estabilización de las denominadas "tasas chinas") ${ }^{3}$ y el aumento de la conflictividad laboral; y como parte fundamental de este proceso, la emergencia del sindicalismo de base (Meyer y Gutiérrez, 2005; Castillo, 2007; Cotarelo, 2009; Eskenazi, 2011). Efectivamente, ya desde 2004 comienzan a observarse conflictos sindicales por empresa que presentan la característica de ser dirigidos por delegados gremiales de base en forma independiente o en abierta oposición a la conducción sindical. Semana Santa de 2004 sorprendió a la ciudad de Buenos Aires con las cinco líneas del subterráneo y premetro completamente paralizadas, los túneles tomados y piquetes en las cabeceras. ${ }^{4}$ La primera huelga de esa envergadura bajo el gobierno de Kirchner. El resultado del conflicto fue, por una parte, la obtención de la implementación de la jornada de 6 horas de trabajo para todo el personal (y, por consiguiente, 500 nuevos puestos de trabajo en Metrovias); por otro, el freno de la decisión de la empresa de colocar máquinas expendedoras de boletos; y por último, pero de mucha importancia para la vida política sindical, el reconocimiento del cuerpo de delegados opositor a la dirección de la UTA, como representante de los trabajadores en la negociación. En diciembre del mismo año, los trabajadores del subte vuelven a salir al paro por aumento salarial. En medio del clima de lucha, se incorpora un nuevo sector antes ausente: los trabajadores "tercerizados" de la empresa TAYM que presta servicios de limpieza para Metrovias. La Navidad de 2004 encuentra a los tercerizados del subte realizando la primera medida de fuerza por pase a convenio de la UTA. Alli comienza una serie de paros y movilizaciones que dos años después, en 2006, concluirá con el total de trabajadores de las empresas tercerizadas bajo convenio de la UTA.

Clarin del 5 de diciembre de 2004 refleja de este modo el clima de huelgas en que emerge el sindicalismo de base:

El aumento conseguido por los telefónicos, el paro de los

3. Según cifras oficiales, entre "2002 y 2006 el crecimiento acumulado de la economía alcanzó a más del $40 \%$ y los sectores productores de bienes acumularon un crecimiento mayor al 50\%, descollando, entre ellos, el incremento de la construcción $(146 \%)$ y la industria (52\%). El impacto del crecimiento económico sobre el empleo fue, esta vez, asombrosamente intenso. La elasticidad empleo/producto inusitadamente alta, sobre todo en el comienzo de la recuperación, se mantiene muy por arriba de la existente durante la década precedente..." (Chitarroni y Cimillo, 2007).

4. El conflicto se desata a partir de que la dirección de la UTA (Unión Tranviaria Automotor) firma un acta-acuerdo con Metrovías en el que se establece la reducción de la jornada laboral de los boleteros a 7 horas diarias a cambio de la instalación de máquinas expendedoras de boletos. El cuerpo de delegados del subte, opositor a la dirección de la UTA, decide parar las cinco líneas para impedir que se coloquen las máquinas y exigir que se incluya a los boleteros dentro de la jornada de 6 horas. 
maestros bonaerenses y los empleados estatales, las protestas de los ferroviarios y los trabajadores del subte, la huelga de camioneros [...]. En los últimos días, los reclamos gremiales parecieron haber vuelto con fuerza y, según datos del Ministerio de Trabajo, actualmente más de la mitad de los conflictos sociales tienen origen sindical. (Clarín, 5-12-04)

En febrero de 2005, los trabajadores del Subte consiguen un aumento salarial promedio del $44 \%$. Con estos logros, y con la visibilidad pública que otorga el hecho de ser trabajadores de un servicio público privatizado que transporta más de un millón y medio de personas por día, el cuerpo de delegados del subte se transforma en una referencia de lo que la prensa denominó "sindicalismo de base". Clarín del 13 de febrero de 2005 anuncia en tapa:

"Salarios: Buscan encauzar las negociaciones [...] Preocupados por la dimensión que alcanzó la semana pasada el conflicto gremial en los subterráneos, el Gobierno, la CGT y la UIA apuran la firma de un acuerdo que ponga marco a la discusión salarial."

En julio de ese año la comisión interna del Hospital Garraham encabeza un duro conflicto por aumento salarial que alcanzó repercusión nacional y fue caratulado por parte del Ministro de Salud con el mote de "terroristas sanitarios". El 2005 será, efectivamente, el año en que se registra el número más elevado de protestas desde 1990.

Es en este marco que debe analizarse la politica de reunificación de la CGT y de relegitimación de los sindicatos en la figura de Hugo Moyano. El 14 de julio de 2004 (3 meses después de la primera huelga del subterráneo), se reúne el congreso general ordinario de la CGT y vota al líder camionero como secretario general. El 14 de julio de 2005, Moyano asume la conducción de la central sindical terminando el período transitorio de gobierno tripartito que compartía con Susana Rueda (Sanidad), referente de los denominados "gordos", y José Luis Lingieri (Obras Santiarias), perteneciente a los “independientes”. De alli hasta 2011, Moyano será lo que los propios kirchneristas denominaron el "aliado estratégico" del gobierno nacional. Es decir que, en sentido contrario a las interpretaciones que sostienen que el fortalecimiento de los sindicatos fue una politica gubernamental implementada, por generación espontánea, de arriba hacia abajo, la cronología muestra que el giro desde una politica de fuerte arbitraje gubernamental directo hacia una política de relegitimación de la institución sindical (en la figura de Hugo Moyano y la CGT) debe explicarse, en parte, por la presión que comienza a ejercer en 2004 el surgimiento de conflictos sindicales dirigidos por delegados de base que actúan por fuera (o en abierta oposición) de las cúpulas sindicales. Presión que tiene como 
demanda central el aumento salarial por arriba de lo establecido por el poder ejecutivo tanto en los aumentos de suma fija por decreto como en las instancias de pacto social en los Consejos del Salario. El "giro hacia los sindicatos" pudo observarse también en dos aspectos de la Ley de Ordenamiento Laboral ( $\mathrm{N}^{\circ} 25.877$ ) que, en 2004, derogó la Ley de Empleo Estable ("ley banelco", N ${ }^{\circ}$ 25.250): la restitución del principio de ultraactividad y de la prevalencia de negociaciones de ámbito mayor. ${ }^{5}$ Ambas disposiciones fortalecian la gravitación de la CGT en la regulación de las condiciones salariales y de trabajo. Es a partir de esta necesidad de regular con más eficacia los reclamos salariales que las negociaciones colectivas pasan al centro de la escena y comienza la escalada ascendente de homologaciones. Durante 2005 se firmaron 568 acuerdos, un 63\% más que en 2004 (mientras que 2004 habia presentado una leve disminución respecto de 2003), y en 2006 fueron avalados 930 convenios y acuerdos, la cifra más alta desde 1991. De alli hasta 2010, las negociaciones colectivas ofrecen cifras contundentes. Según los datos del Ministerio de Trabajo (MTEySS) la firma de negociaciones colectivas ha presentado una constante curva ascendente, acumulando un total de más de 7.000 unidades negociadas. ${ }^{6}$ Esto establece un promedio anual de alrededor de 1.000 negociaciones colectivas, lo que quintuplica el promedio de menos de 200 unidades negociadas por año durante la década del 90 . Esto ha refractado, a su vez, en un aumento sistemático de la cantidad de trabajadores cubiertos por los convenios colectivos, los cuales pasaron de 3 a 5 millones de asalariados entre 2003 y 2010 en el sector privado no agricola. ${ }^{7}$

La centralidad de las negociaciones colectivas no eliminó, de ningún modo, el tutelaje presidencial directo. Por el contrario, la búsqueda de una regulación más eficaz de las negociaciones por salario dio como resultado la fórmula que signará el período hasta 2011: paritarias + topes salariales.

\section{Negociación tutelada}

El año 2006 inaugura las negociaciones paritarias con el tope del

5. El principio de ultraactividad estipula que, ante la ausencia de nuevos convenios colectivos, es válido el último homologado. Este principio, que siempre se mantuvo en la letra, fue sin embargo modificado en la práctica durante la década del 90 . La prevalencia de negociaciones de ámbito mayor establece que un acuerdo o convenio firmado a nivel de rama prevalece sobre un acuerdo o convenio firmado a nivel de empresa.

6. Véase http://www.trabajo.gov.ar/left/estadisticas/negCol/index.asp

7. Las estadística del MTEySS no contabilizan las negociaciones colectivas del sector docente como así tampoco de la administración pública nacional. 
19\% acordado entre la CGT, el gobierno y los empresarios, lo cual logra actuar como pauta de aumento salarial para el conjunto de los trabajadores registrados y descomprime la oleada de conflictos sectoriales y por empresa que habian comenzado en 2004. Es interesante señalar una cuestión respecto de 2006 para calibrar la importancia de los topes salariales en la política gubernamental. Éste es el año en que los salarios de los trabajadores registrados ${ }^{8}$ alcanzaron los niveles previos a la devaluación (Lindemboin, 2007; Basualdo, 2008; Bach, 2008; Marticorena, 2011). A partir de allí, la combinación entre aceleramiento inflacionario y regulación estatal del incremento del salario real logró que la tendencia promedio de los salarios reales sea al estancamiento en los niveles de 2001.

En 2007 se profundiza la política de topes salariales (fijado ese año en $16 \%$ ) a partir de la aceleración de la inflación como uno de los primeros sintomas de agotamiento del denominado "modelo kirchnerista" (Anino, 2008). Esto marcará el surgimiento de dos nuevas políticas de arbitraje presidencial directo en la regulación del salario real: la intervención del Instituto Nacional de Estadísticas y Censos (INDEC), lo que obstaculiza, entre otros cálculos, el de la inflación y por ende del salario real en Argentina; y la implementación de una política represiva selectiva para los conflictos de trabajadores que se desarrollaran por fuera de la dirección de la CGT moyanista. Caso emblemático de esto es el del Casino Flotante de Buenos Aires cuya comisión interna (opositora al SOMU) encabezó un muy duro conflicto, en el que fueron reprimidos seis veces por Prefectura y tuvieron que enfrentar, además de a la patronal, a seis direcciones sindicales que se declararon en contra de la huelga. Otros casos que expresan este cambio fueron el intento de desafuero del delegado de subte Néstor Segovia y la ofensiva de la dirección de la UTA contra al cuerpo de delegados del subte en su conjunto; el ataque por parte de una patota de la UTA a los delegados y activistas de la línea 60; el ataque de la patota de la UOM a los obreros de la autopartista Dana Spicer (ex Eaton) en la Zona Norte del conurbano; y la muy dura lucha de los obreros de Mafissa (ex Hilandería Olmos) en el Gran La Plata que, luego de acampar frente a la planta en protesta por los despidos, tomaron la fábrica y fueron desalojados por un operativo policial de más de 700 efectivos para una toma realizada por 18 obreros.

Entre fines de 2008 y mediados de 2009 la dinámica entre negociación colectiva, arbitraje presidencial directo y conflictividad laboral se modifica por una serie de factores políticos y económicos. A nivel político, la crisis del gobierno de Cristina Fernández luego del denominado "conflicto

8. Un año después, en 2007, esos niveles serán alcanzados por el promedio de los trabajadores aunque con una fuerte heterogeneidad interna. 
del campo", lo que derivó en la derrota electoral de 2009. A nivel económico, el impacto de la crisis internacional que generó desaceleración de la economía, caída de la inflación (enfriamiento) e incluso una oleada de despidos de alrededor de 250 mil puestos de trabajo. En esta coyuntura emergió quien se constituirá en otro referente del sindicalismo de base: la comisión interna de Kraft Foods. A partir del despido de más de 150 trabajadores, la mayoria de ellos activistas sindicales que habian puesto en pie el cuerpo de delegados, se desarrolla un conflicto que incluye 38 dias de paro, ocupación de la planta y desalojo violento con la infantería (Varela y Lotito, 2009; Cambiasso, 2011). El conflicto de Kraft mostró dos cosas: a) que el sindicalismo de base, cuya conflictividad había sido aplacada hacia 2006, continuó extendiéndose en forma molecular en los lugares de trabajo; b) que ese "movimiento" que se había constituido en el período 2004-2006 como expresión de la lucha por la ruptura del techo salarial, podía convertirse, en "época de crisis", ${ }^{9}$ en obstáculo de aplicación de ajustes.

El año 2009 también resulta un año sumamente ilustrativo respecto de la función que juega el tope salarial impuesto por el gobierno en acuerdo con la dirección moyanista. Por primera vez desde el retorno de las negociaciones colectivas, el gobierno nacional no establece una pauta de aumento salarial. Esto se explica porque, en una coyuntura recesiva, la negociación "libre" redunda en beneficio de los empresarios en la medida en que se ajusta a la evolución de la producción y del poder de los sindicatos. Entre 2008 y 2009 sólo cuatro ramas de actividad de la industria manufacturera presentaron crecimiento, lo que hizo que la mayoria de las patronales argumentara la imposibilidad de subir salarios y blandiera la amenaza de despidos o suspensiones como recursos de negociación a la baja.

En 2010, recuperación de la economía mediante, retornan la puja por aumento salarial y, con ella, los topes salariales fijados por el gobierno, Moyano y el empresariado. La única rama que firma un aumento salarial 10 puntos por encima del tope del $25 \%$ es la alimentación, debido al conflicto con paro y corte de Panamericana encabezado por la comisión interna de Kraft. De alli en adelante, las comisiones internas opositoras en el gremio alimenticio irán creciendo. Al respecto, es interesante lo que declaró Daniel Funes de Rioja, representante de la Coordinadora de las industrias de Productos Alimenticios (COPAL) el 7 de febrero de 2013 al diario Ámbito Financiero:

9. Vale aclarar que la industria de la alimentación fue una de las cuatro ramas de la industria manufacturera que no sólo no mostró recesión durante 2008 y 2009, sino que mostró claro crecimiento. Esto refuerza la hipótesis (que consideramos probada) de que el ataque de Kraft Foods a los activistas y delegados tuvo como motivo el intento de desarticular el proceso de organización de base en la planta de Pacheco. 
Ambos sectores [cámara empresaria y cámara de sindicatos alimenticios] representan a los productores y a los gremios de todas las empresas de alimentos y bebidas, y se debaten hace años en acuerdos de aumentos salariales importantes para frenar las embestidas de las "comisiones internas" de izquierda dura que pueblan las grandes compañias del rubro.

Hacia 2012 esta "izquierda dura" conformará la lista Bordó a nivel nacional y obtendrá casi el $40 \%$ de los votos del gremio.

El año 2010 termina con un hecho que sacudió la escena nacional: una patota de la Unión Ferroviaria asesina al militante del Partido Obrero Mariano Ferreyra en medio de una jornada de lucha de los tercerizados del ferrocarril ex Roca (Rojas, 2011). El asesinato puso en evidencia tres elementos del "modelo", aunque invisibilizados: la lucha de los tercerizados, la connivencia entre el Estado y la burocracia sindical y la utilización de patotas sindicales como herramienta de disciplinamiento y represión paraestatal.

\section{La demonización}

El año 2011 marca un punto de inflexión en la política gubernamental hacia los sindicatos, signado por un arbitraje gubernamental directo mucho más marcado y por el comienzo de reversión de la política de relegitimación de los sindicatos como institución del régimen político post-devaluación. Esto puede observarse a través de diversas variables. En relación a la homologación de las negociaciones colectivas y según el último informe anual disponible en el MTEySS, la tendencia progresiva comienza a revertirse y se observa un descenso de $8,5 \%$ respecto del año anterior. Según los datos del primer trimestre de 2012, la tendencia a la baja se profundiza descendiendo en un $28 \%$ la cantidad de homologaciones respecto del mismo período del año anterior. ${ }^{10}$ Este cambio de politica por parte del gobierno tiene dos explicaciones principales: la aceleración de la inflación (y el intento gubernamental de frenar los aumentos salariales) y la ruptura del gobierno de Cristina Fernández con Hugo Moyano (y el intento gubernamental abierto de quitar poder de negociación a los sindicatos).

En cuanto a la inflación, el año 2011 marcó el inicio de un aceleramiento que continúa hasta la actualidad. El aumento progresivo del

10. Es importante señalar que la estructura sindical en Argentina (heredada del primer peronismo) establece que el Estado nacional, a través del Ministerio de Trabajo, es quien tiene la potestad de homologar (darle fuerza de ley) las negociaciones colectivas acordadas entre empresarios (o cámaras empresarias) y sindicatos (organizados en Argentina por rama de actividad). 
índice inflacionario hacia 2011 alcanzó poco menos del 25\% anual, en 2012 superó el 25\% y en los primeros meses de 2013 se transformó en el centro del debate político en el país al haber acumulado sólo en el mes de enero alrededor de 2,6\%. Este aumento de la inflación es la expresión más visible (junto con el déficit en las cuentas fiscales) del agotamiento del "modelo" más en general que se manifestó en una caída del crecimiento del PBI desde 8,9\% en 2011 a 1,8-1,9\% en 2012. Es en este contexto que se dan los primeros roces y posterior ruptura del gobierno de Cristina Fernández con su "aliado estratégico", Hugo Moyano. Los motivos inmediatos de la ruptura hay que buscarlos en la asincronía entre el lugar de Moyano (y con él de un sector de la dirigencia sindical peronista) dentro del régimen kirchnerista y el lugar de este mismo sector dentro del Partido Justicialista (PJ). Es decir, un desfasaje entre el peso social y politico que alcanzaron los sindicatos en la post-convertibilidad y su peso político dentro del partido de gobierno y, por ende, en las negociaciones por la sucesión gubernamental. Esta asincronía estalló bajo la forma de la lucha por las candidaturas electorales al interior del Frente para la Victoria. Las elecciones de 2011 significaron una derrota para el sector sindical y un triunfo relativo del sector territorial del PJ, lo que dejó cierta tensión entre el moyanismo y el gobierno nacional. Esa tensión se transformó en ruptura inmediatamente después de las elecciones de octubre de 2011. Cristina Fernández, bajo el supuesto de su sustento en el 54\% de los votos, comenzó a enarbolar un discurso de fuerte descalificación hacia los reclamos obreros y con ellos hacia los sindicatos. Para 2012 la ruptura estaba consumada y con ella se conformaba un escenario sindical atípico en el país: la existencia de 5 centrales sindicales, 3 de ellas opositoras y 2 oficialistas. ${ }^{11}$ El pasaje de Hugo Moyano a la oposición aceleró el cambio de política del gobierno nacional respecto de los sindicatos y de los reclamos salariales en su conjunto, profundizando el arbitraje presidencial directo. La negativa del Ministerio de Trabajo a la homologación de convenios y acuerdos, que comienza en 2011 y se profundiza en 2012, es una forma de ejer-

11. El lock out de las patronales agrarias y la polarización política y crisis del gobierno que produjo redundaron en dos rupturas dentro del movimiento sindical. La ruptura de la CTA entre un ala abiertamente oficialista conducida por Hugo Yasky (docentes), y un ala opositora ligada al Frente Amplio Progresista (FAP), conducida por Pablo Micheli. Esta ruptura se terminará de definir en 2010 en oportunidad de las elecciones generales de la central en la que ambas fracciones se acusarán de fraude, mientras el Ministerio de Trabajo dará el triunfo al ala yaskista. A su vez, el "conflicto del campo" también producirá el fraccionamiento de un sector minoritario de la CGT encabezado por Luis Barrionuevo (gastronómico) y Momo Venegas (peones rurales) que conformarán la CGT Azul y Blanca, en disconformidad con la alineación de Moyano con el gobierno nacional durante el conflicto. 
cer el arbitraje gubernamental directo ante la evidencia de pérdida de capacidad para pactar topes salariales con las direcciones sindicales divididas y con un sector importante en la oposición.

El año 2013 comienza con un hecho que refuerza la tendencia: ante el reclamo de los docentes por un aumento salarial del 30\%, el MTEySS cierra unilateralmente la paritaria a través de un decreto que establece un aumento del $22 \%$. Esto obligó a la oficialista CTERA a oponerse a la política gubernamental y plantear el no inicio del año lectivo. Al momento de escribir este artículo, el conflicto sigue en curso.

\section{Precariado}

Para analizar la ruptura del gobierno con Moyano es importante diferenciar los motivos inmediatos de los elementos estructurales que dicha ruptura expresan. Hemos dicho más arriba que los motivos inmediatos están signados por la asincronía entre la nueva fuerza de los sindicatos y su reconocimiento dentro del PJ (y del sistema de alianzas del kirchnerismo). Pero sería erróneo pensar que este desfasaje es producto de una voluntad antisindical o antiobrera por parte del cristinismo (sin negar que esos elementos estén presentes). Existen factores estructurales que están en su base: la contradicción entre la nueva fuerza social de los trabajadores y el mantenimiento de las condiciones de explotación heredadas de los 90. Desde 2003, los trabajadores en Argentina viven un proceso de fuerte recomposición social y gremial, consistente en la incorporación de alrededor de 4 millones de puestos de trabajo (con su consiguiente obturación relativa del efecto disciplinador del desempleo masivo) y el ejercicio de luchas reivindicativas (con su consiguiente aumento de las expectativas). Esa nueva fuerza social y su experiencia gremial chocan contra el mantenimiento de las condiciones de explotación que dejó la década neoliberal, lo que se manifiesta, principalmente, en la continuidad de una alta precarización y fragmentación obrera. Es la política de mantenimiento de las conquistas que el capital logró sobre la clase trabajadora durante el neoliberalismo, como politica de Estado del "modelo kirchnerista", lo que opera como límite objetivo para el fortalecimiento de los sindicatos por "arriba". Si bien esta contradicción está presente desde el inicio, el agotamiento de las variables económicas entre fines de 2011 y 2012 la transformaron en crisis y precipitaron el giro antisindical del gobierno.

Establecer el carácter constituyente de esta contradicción en la política kirchnerista permite ponderar dos cuestiones centrales del nuevo fortalecimiento sindical. La primera, que la visión de retorno de los sindicatos como reversión tout court de su pérdida de centralidad política en los 90 implica una disociación entre formas institucionales 
y bases sociales. Cuando hace casi diez años, Steven Levitsky (2005) analizó el pasaje del PJ de un partido sindical a un partido clientelar, lo hizo estableciendo, justamente, la relación entre modificaciones estructurales y su expresión en formas institucionales. Diez años después, sería ingenuo (o abiertamente tendencioso) sostener el retorno institucional de la "columna vertebral" del peronismo sin analizar las contradicciones entre ese retorno y la continuidad relativa de las derrotas sufridas por la clase obrera en el neoliberalismo. La segunda, es que esta contradicción constituye la base objetiva de aparición del sindicalismo de base. El sindicalismo de base expresa el desfasaje entre la recomposición social y gremial de los trabajadores y la reversión de las derrotas de los 90. Y lo hace alli donde ese desfasaje se vuelve más conflictivo: el lugar de trabajo.

Para analizar el mantenimiento de las condiciones de explotación neoliberales nos centraremos en la continuidad de la precarización laboral. Utilizaremos un concepto amplio de precarización que afecta tres dimensiones de la relación de explotación: la relación contractual (desde el trabajo estable hasta el trabajo no registrado); el proceso de trabajo (flexibilización en la asignación del tiempo de trabajo y flexibilización en la organización del trabajo); y la organización sindical (grados de sindicalización y presencia organizativa en el ámbito laboral).

En lo que hace a las divisiones entre trabajadores no registrados, trabajadores precarios y trabajadores estables, la falta de credibilidad de las estadísticas oficiales hace sumamente complejo un análisis de la situación del mercado laboral en profundidad. ${ }^{12}$ Sin embargo, hay coincidencias en afirmar que en la actualidad la tasa de trabajo no registrado se encuentra entre el $36 \%$ y $40 \%$. Es interesante observar aquí que la tasa de trabajo no registrado en la década del 80 era del 25\% y ascendió abruptamente al 40\% hacia el final de la década del 90. Es decir que, luego de nueve años de crecimiento al 7,6\% promedio (de 2002-2010), la tasa de trabajo no registrado se encuentra en niveles cercanos a los alcanzados luego de las contrarreformas neoliberales. Si a las cifras de trabajo no registrado se le agregan otras variables de precarización laboral, como los trabajadores con contratos temporarios (inestables) o también los asalariados y cuentapropistas cuyos ingresos están por debajo del salario mínimo (que marca la línea de pobreza en el país), encontramos que la precariedad laboral afecta al 53,6\% de la fuerza laboral. Si el cálculo se realiza sobre la fuerza de trabajo asalariada, el porcentaje alcanza el 55,5\% (Lozano y Raffo, 2012).

Por otra parte, si tomamos como indicadores de precariedad laboral

12. En 2009, el INDEC deja de publicar las bases de la Encuesta Permanente de Hogares, obstruyendo así el acceso a los datos de trabajo no registrado en el país. 
la subocupación (es decir, aquellos trabajadores que trabajan 6 horas y desean trabajar más) encontramos que en 2008 constituyen el 9,2\% de la PEA (Lozano et al., 2008). Si a esa cifra le agregamos los trabajadores directamente desocupados, el total aumenta al 16\%. Como contrapartida a la subocupación y desocupación del $16 \%$, observamos que el promedio de horas trabajadas es de 12 horas, habiendo una variación entre los trabajadores no registrados -que estarian realizando jornadas promedio de 12,5 horas diarias-y los registrados -cuya jornada estaria situada en 11,7 horas de trabajo promedio-. Esta fragmentación en el colectivo de clase repercute en diferencias salariales que devienen de los diversos grados de precarización laboral. En este campo, vemos que

en 1998 el sector "formal" tenía ingresos un 20,3 \% por encima del promedio de ingresos del conjunto. En 2006 este porcentaje se encontraba en un nivel levemente superior, un $22,3 \%$. En lo que hace al sector "informal", recibia en 1998 ingresos un $34,2 \%$ inferiores al promedio, una cifra que se amplió en 2006 hasta el -40,4\%. Por el contrario, los ocupados del sector "público tradicional" tenían en 1998 ingresos un $18,7 \%$ por sobre el promedio y en 2006 vieron una ampliación de este porcentaje al 27,7\%. (Castillo y Lizarrague, 2009).

Si miramos las diferencias salariales en su conjunto, encontramos que el promedio de salario de los trabajadores "no registrados" representa hoy la mitad del de los registrados.

En lo referido a la precarización laboral a través de cláusulas de "flexibilización interna" (jornada y organización del trabajo), el análisis de la los Convenios Colectivos de Trabajo (CCT) homologados entre 2003 y 2009 encuentra que, en relación a la jornada de trabajo, "de los 785 convenios colectivos celebrados entre 2003 y 2009 al menos 405 incorporaron una o más cláusulas que la flexibilizan, lo que implica un 51,6\% del total" (Campos y Campos, 2010: 56). Esto resulta especialmente interesante porque, si se compara con los CCT celebrados en la década del 90 (de 1991 a 1999), se encuentra que el 46,6\% de aquellos incluían cláusulas de flexibilización que afectaban la jornada laboral. Es decir que, entre ambos períodos, el porcentaje de cláusulas flexibilizadoras de la jornada laboral es mayor en la actualidad $(51,6 \%$ para el periodo 2003-2009; 46,6\% para 1991-1999), y el mecanismo más utilizado para la flexibilización de la jornada de trabajo es, antes como ahora, la implementación de los turnos rotativos o americanos. Por otra parte, si tomamos en cuenta las cláusulas flexibilizadoras relativas a la organización del trabajo, encontramos que "se presentan en al menos 375 negociaciones, lo que representa el $47,8 \%$ de los convenios 
homologados, con una presencia muy importante de las cláusulas que establecen la polivalencia o multifuncionalidad de tareas" (Campos y Campos, 2010: 57). Tomando la década previa, vemos que las cláusulas de flexibilización referidas a la organización del trabajo no sólo no disminuyeron sino que aumentaron, conformando el 39,05\% entre 1991-1999 y el 47,8\% en el período 2003-2009. Asimismo, si tomamos la segunda mitad de la década pasada, podemos observar que en esos cinco años que van de 1995-1999 se concentraron la mayor cantidad de cláusulas de flexibilización a nivel de la organización, alcanzado un $49,07 \%$, cifra similar a los actuales $47,8 \%$.

Tomadas de conjunto, el análisis de las cláusulas de los actuales convenios colectivos permite concluir que, lejos de una reversión de las condiciones de trabajo flexibilizadas que fueron legalizadas en la década del 90, lo que se encuentra es una tendencia a su continuación y profundización. Aquí es importante una aclaración, a riesgo de realizar deducciones lineales: la continuidad que se observa en los convenios no implica (de hecho no ha implicado) un reflejo equivalente de demandas contra la flexibilización en la conflictividad laboral. Por el contrario, el centro de los conflictos laborales ha sido la lucha salarial. El salario ha ocupado el lugar del objeto negociable, incluso a costa del mantenimiento o profundización de las condiciones de explotación noventistas.

En tercer y último lugar, un elemento central para el análisis de la precarización de la situación de los trabajadores es el que refiere a los niveles de sindicalización. Como es sabido, una de las características de la clase obrera en Argentina es su alta tasa de sindicalización. En la actualidad esa tasa es de alrededor de 37\% de los trabajadores privados registrados en el país. Algunos analistas comparan esta cifra con las cifras de sindicalización en Francia o incluso en otros países de América Latina como Brasil, para destacar el alto nivel de sindicalización como parte del nuevo "modelo laboral". Sin embargo, si se miran las cifras en términos histórico-comparativos, lo que encontramos es que este $37 \%$ está en los mismos niveles de la segunda mitad de la década del 90. Según la investigación llevada a cabo por Senén González, Trajtemberg y Medwid (2010), durante los 90 se consumó una baja exponencial de la tasa de afiliación como parte de la política de ataque a las condiciones de vida y trabajo de los asalariados. En función de las series reconstruidas, estiman que en 1990 la tasa de afiliación sindical era de 65,6\% (muy similar a la tasa en 1985, que era de 67,5\%), mientras que en 1995 la cifra era de $38,7 \%$. Es decir, casi 30 puntos porcentuales menos en sólo cinco años. El actual 37\% no sólo no marcaría una reversión de la política de desindicalización de los 90 , sino que indicaría su continuidad (aunque en términos absolutos, la cantidad de asalariados afiliados sea mayor). Esta continuidad se expresa también en la debilidad de 
la organización sindical a nivel del lugar de trabajo. Si bien no existen series estadísticas constantes que permitan establecer comparaciones a mediano y largo plazo, los datos construidos por el MTEySS permiten considerar su carácter limitado. Si miramos la situación actual, según la Encuesta de Indicadores Laborales (realizada por el Ministerio de Trabajo de la Nación) a cifras de 2008 sólo el 14,2\% de las empresas tiene por lo menos un delegado. Si desgranamos esa cifra según la envergadura de la empresa, vemos un degradé en el que va menguando la existencia de delegados sindicales según el tamaño de la empresa. En las grandes empresas (de 200 trabajadores o más), el 63,3\% tiene algún delegado; en las empresas "medianas" (de 50 a 200 trabajadores), sólo el 31\% tiene algún delegado; mientras que las empresas chicas (entre 10 y 49 trabajadores) un ínfimo porcentaje de 8,5\% tiene algún delegado.

Este último elemento es un factor fundamental para no establecer relaciones mecánicas entre el mantenimiento de la precarización y el surgimiento del sindicalismo de base. El sindicalismo de base es, por una parte, expresión de las contradicciones entre la recomposición social de la clase trabajadora en Argentina y el mantenimiento de las condiciones de explotación neoliberales. Por otra, expresión de la contradicción entre esta recomposición social y la continuidad de la pérdida de legitimidad de los sindicatos en los 90 .

En este contexto se desarrollan dos elementos que trataremos en el próximo apartado y terminarán de dar forma al sindicalismo de base: la "generación 2001" como centro de la fuerte renovación generacional en el mundo del trabajo, producto del aumento exponencial del empleo, y la presencia de la izquierda de origen marxista en el movimiento obrero.

\section{Peronistas eran los de antes}

Uno de los rasgos que caracteriza este sindicalismo de base es que está constituido por jóvenes de entre 25 y 35 años, lo que denominamos "la generación 2001". Esto es importante porque permite comprender una dimensión ideológico-política central del sindicalismo de base actual, que lo diferencia de otros períodos de la historia del movimiento obrero en Argentina. Estos "jóvenes que se vuelven militantes de sus derechos" (Collado y Varela, 2008) expresan una generación que combina tres elementos. En primer lugar, no cargan, en su experiencia inmediata, con las derrotas de la década del 90, particularmente la derrota que significó la hiperinflación del 89 y las contrarreformas neoliberales posteriores, cuya consecuencia más sentida fue la desocupación masiva. Esta ausencia de "memoria de las derrotas" (que tiene como contraparte falta de experiencia en organización y luchas) se combina con la ausencia de una identificación política definida. A diferencia de lo que sucedió desde 1945 
en adelante en Argentina, donde la identificación política e ideológica mayoritaria de la clase obrera fue el peronismo, esta nueva generación no expresa esta adhesión ni sentimental ni político-ideológicamente. Lo que se observa, más bien, es un cierto vacío de identificaciones políticopartidarias claras (Varela, 2009; AA.VV., 2007). Esto no es sorprendente si tenemos en cuenta que los jóvenes, que de 2004 en adelante formaron parte del proceso de politización sindical en el lugar de trabajo, lo hicieron sobre el fondo de la fuerte despolitización que significó la década del 90 para la vida sindical. Sin embargo, esta generación tuvo un "bautismo político" que le dará su sello generacional: las jornadas de diciembre de 2001, con su puesta en crisis del conjunto de las instituciones del Estado, la legitimación parcial de la acción directa como herramienta de lucha y aspectos de democracia directa plasmados en el asambleísmo. Pero el 2001 no es sólo crisis del Estado, lucha callejera y repudio a las instituciones de la democracia de 1983, es también la presencia de la "extrema izquierda" o "izquierda clasista" (encarnada en partidos de tradición trotskista) ${ }^{13}$ en los principales fenómenos de la lucha de clases y organización popular. Esto se observa, por un lado, en el desarrollo del movimiento piquetero donde, en el marco de la influencia de distintas tradiciones de izquierda, ${ }^{14}$ el Partido Obrero (PO) y el Movimiento Socialista de los Trabajadores (MST) ${ }^{15}$ lograron una fuerte inserción en el proceso de lucha y organización de los trabajadores desocupados; ${ }^{16}$

13. En Argentina existen varios grupos de tradición trotskista, aquí nos referimos al Partido Obrero y el Partido de Trabajadores Socialistas, por ser los dos con mayor influencia en la lucha y organización de los trabajadores en el último período, el PO en el movimiento piquetero y el PTS en las fábricas recuperadas y el sindicalismo de base.

14. Dentro del campo de la izquierda, tuvieron influencia en el movimiento piquetero el Partido Comunista Revolucionario (PCR), de tradición maoísta, a través de la Corriente Clasista y Combativa (CCC), y el Movimiento de Trabajadores Desocupados (MTD), de tradición autonomista, que luego de una serie de rupturas quedó dividido entre un sector que se volvió oficialista y el Frente Popular Dario Santillán (FPDS).

15. En la actualidad, el MST ha abandonado casi completamente toda referencia a la izquierda revolucionaria y/o el marxismo. En 2008, durante el lock out de las patronales agrarias, apoyó públicamente a estas últimas. Desde 2010 se integró en Proyecto Sur, frente electoral encabezado por Pino Solanas. En la conformación de alianzas de cara a la elecciones legislativas de este año (2013) están en negociaciones para un frente electoral para la Ciudad de Buenos Aires entre Proyecto Sur y Elisa Carrió de la Coalición Cívica.

16. La actuación de la izquierda clasista en el movimiento piquetero, encabezada por el PO, estuvo marcada por dos tensiones. La primera, la tensión entre la adhesión al programa de independencia política de la clase obrera respecto del Estado y la dependencia de la administración de planes sociales estatales. La segunda, la tensión entre el programa de unidad de los trabajadores y la política de construcción de co- 
por otro lado, en las fábricas recuperadas, en las que el Partido de Trabajadores Socialistas (PTS) logró una fuerte influencia, particularmente en Zanon ${ }^{17}$ que se constituyó en referente nacional e internacional del ala izquierda del movimiento con el programa de "nacionalización bajo control obrero". Es decir, la "generación 2001" se desarrolla en un clima de época en que la izquierda que se reivindica revolucionaria es parte del tablero político del país a través de su inserción en las luchas sociales de la última década y media. Esa inserción de la izquierda clasista es también parte constituyente del sindicalismo de base actual.

Si bien es de extrema dificultad su medición estadística, una serie de estudios permiten cierto acercamiento al fenómeno. En el ámbito académico se encuentran diferentes estudios de caso sobre las ramas de la alimentación, subterráneos, salud, automotrices, neumáticos, etc. en los que la presencia de la izquierda en el sindicalismo combativo o de base se señala con mayor o menor profundidad (Guevara, 2012; Cambiasso, 2011; Longo, 2011; Montes Cató y Ventrici, 2011; Duhalde, 2012; Varela y Lotito, 2009; Varela, 2008). Por otra parte, es también interesante analizar los datos del Observatorio del Derecho Social de la CTA que, en su medición de la conflictividad laboral, destaca una variable que no es medida en otras bases de datos: conflictos laborales que fueron conducidos en ausencia de representantes sindicales o en confrontación con ellos. Si bien esta "categoria" no es idéntica a "presencia de la izquierda", en la práctica tienden a coincidir. Si se miran los datos de 2007, se encuentra que un $14 \%$ de los conflictos laborales son conducidos por direcciones no reconocidas institucionalmente $u$ opositoras a la dirección sindical. Si se miran los datos de 2010, este porcentaje ha aumentado al 17\%. Periodísticamente, de 2005 en adelante se encuentran una serie de notas de coyuntura que resaltan el fenómeno, así como también dossiers dedicados a problematizar la existencia del "sindicalismo indomable". Como señala un periodista especializado, "basta salir a la calle para saber que las medidas de fuerza se multiplican en sectores clave, sobre todo en el transporte, porque alli hay cuerpos de delegados indomables". ${ }^{18} \mathrm{Si}$ bien efectivamente el sector servicios es el más visible (por su particular relación entre actividad laboral y usuarios), lo cierto es que es el sector fabril (cuyos conflictos muchas

laterales partidarias que operaron dificultando dicha unidad. Para un análisis crítico de la actuación de la izquierda en el movimiento piquetero, véase Werner y Aguirre (2004). Para un análisis de la izquierda revolucionaria en el período de conjunto, véase Castillo y Rosso (2012).

17. Fernando Aizicson, en su tesis sobre Zanon, realiza una recuperación de la relación entre el PTS y Zanón (2009).

18. Ricardo Carpena, "El gremialismo combativo echa raíces", diario La Nación, $29 / 04 / 12$. 
veces quedan encerrados en los muros de la fábrica) el que hace punta en este "gremialismo indomable".

En cuanto a los materiales militantes es posible realizar un seguimiento a partir de dos tipos de fuentes: por una parte, la denominada blogósfera política, tanto en lo que hace a los blogs referenciados en el peronismo ${ }^{19}$ como aquellos referenciados en el trotskismo; ${ }^{20}$ por otra parte, los periódicos partidarios ${ }^{21}$ que permiten observar también la desigual influencia que cada partido tiene en el movimiento obrero a través de la enumeración de la conducción y/o participación en comisiones internas y/o cuerpos de delegados, y conducción y/o participación en listas opositoras en distintos gremios. Por último, esta presencia de la izquierda en la conformación del sindicalismo de base se observa también en la protesta callejera y la emergencia de referentes sindicales con pública militancia partidaria. El conflicto de Kraft de 2009 significó un punto de inflexión en este sentido (Varela y Lotito, 2009). Su prolongación y dureza hicieron que durante más de un mes fuera parte de los medios masivos de comunicación volviendo pública la existencia de dirigentes de izquierda opositores a la conducción nacional del gremio en manos de Rodolfo Daer. Esto hizo que la pregunta por quién conduce la comisión interna de Kraft trascendiera las fronteras de la fábrica y se transformara en una pregunta de interés político, logrando un hecho inédito: la cobertura por parte de los medios masivos de las elecciones de la comisión interna de la planta de Pacheco y del triunfo del ala izquierda encabezada por Javier "Poke" Hermosilla, militante del PTS. El paro del 20 de noviembre de 2012 también mostró a este sindicalismo de base y la influencia de la izquierda en él a escala nacional a través de la televisación de los cortes en Panamericana (zona norte del GBA), con la interna de Kraft y otras fábricas de la zona; el paro en el ferrocarril Sarmiento, cuyo dirigente es Rubén "Pollo" Sobrero, militante de Izquierda Socialista, y los enfrentamientos con la patota de la UTA en la línea B del subterráneo, cuyo referente es Claudio Dellecarbonara, militante del PTS, por mencionar los referentes más relevantes.

Ahora bien, aunque esta inserción de la izquierda en sectores del nuevo movimiento obrero resulta una característica constituyente del retorno de los sindicatos en el país de 2003 en adelante, el año 2012

19. Véase, http://abelfer.wordpress.com/, http://deshonestidadintelectual.blogspot. com.ar, http://rambletamble.blogspot.com.ar/, http://ezequielmeler.wordpress. com/, http://omixmoron.blogspot.com.ar/, http://tirandoalmedio.blogspot.com. ar/, entre otros.

20. Véase, http://elviolentooficio.blogspot.com.ar/, http://www.ips.org.ar/, http:// apuntesdefrontera.blogspot.com.ar/, http://eldiablosellama.wordpress.com/, http:// lasideasnocaen.blogspot.com.ar/, http://puntoddesequilibrio.blogspot.com.ar/.

21. Véase La verdad obrera (PTS), Prensa Obrera (PO), El Socialista (IS), entre otros. 
introdujo un cambio de escala para el sindicalismo de base. Dos elementos explican esta modificación: la consumación de la ruptura entre el gobierno nacional y Hugo Moyano (configurando el inédito mapa de cinco centrales sindicales en el país) y el paro nacional del 20 de noviembre, que mostró un acatamiento superior a lo esperado por las propias cúpulas sindicales, incluso en sectores en los que dirige la burocracia oficialista. Este cambio de escala para el sindicalismo de base se expresó en sectores con conducciones de izquierda que "saltaron las fronteras de las fábricas" y disputaron sindicatos a nivel nacional o provincial. Este es el caso de las elecciones en la Federación Gráfica Bonaerense en abril de 2012, en la que la Lista Naranja-Bordó obtuvo un $29 \%$ de los votos, llegando al $40 \%$ en la Zona Norte del GBA. En mayo se realizaron las elecciones del gremio de la alimentación, donde la Lista Bordó obtuvo un $36 \%$ de los votos, logrando la mayoría en 14 fábricas. En el mes de junio se realizaron las elecciones en el gremio jabonero y la lista Bordó obtuvo un $37 \%$ en las urnas de Capital y GBA. Hacia fin de año se realizaron las elecciones de ATEN (docentes de la provincia de Neuquén), donde el FURA (frente opositor a la conducción yaskista) ganó la seccional provincial. En octubre se realizaron las elecciones del sindicato aeronáutico (APA), en las que la opositora Lista 2 "Desde las Bases" obtuvo el 30\% de los votos en aeroparque Jorge Newbery.

\section{Consideraciones finales}

En una entrevista realizada en octubre de 2011 (pocos días antes del triunfo electoral de Cristina Fernández), Juan Carlos Torre diferenciaba un "peronismo contingente de un peronismo permanente" y afirmaba que los sindicatos son parte fundamental del "alma permanente" del peronismo. Meses después se consumaba la ruptura de Cristina Fernández con Hugo Moyano. Y se consumaba también un cierto desconcierto en sectores del kirchnerismo que defendian la alianza estratégica con el camionero y en sectores de la academia que, desde una perspectiva estatalista, sostenían la tesis de "retorno de un gigante" como pilar de la política gubernamental del "modelo kirchnerista".

Como hemos desarrollado en la primera parte del artículo, dicha ruptura no responde a una contingencia sino que expresa una contradicción constituyente del régimen kirchnerista: la contradicción entre la fuerte recomposición social de los trabajadores (alentada por las variables de la acumulación post-convertibilidad) y el mantenimiento de las condiciones de explotación neoliberales (sobre las que se basa dicha acumulación). Señalar esto no significa decir que la ruptura era necesaria en la forma y en los tiempos en que se dio. La política tiene su relativa autonomía (y, en este caso, sus relativos caprichos). Significa sí 
poner la atención en la contradicción estructural que dicha ruptura pone de manifiesto con la perspectiva de establecer hipótesis que expliquen el pasado reciente, al tiempo que permitan anticipar tendencias a futuro. El retorno de los sindicatos al centro de la escena politica nacional, lejos de una restitución del pasado, contiene las tensiones entre la herencia de los 90, la impronta de las jornadas de 2001 y la nueva fuerza que los asalariados asumieron de 2003 en adelante.

El sindicalismo de base, invisibilizado en las perspectivas "estatalistas", conjuga esos tres elementos y lo hace recuperando una tradición que signó el sindicalismo argentino del siglo XX: la organización sindical de base en el lugar de trabajo. De allí que sea insoslayable a la hora de analizar el nuevo protagonismo sindical. Pero además pone de manifiesto un cuarto elemento, también subvaluado en las investigaciones académicas dominantes: el papel de la "extrema izquierda" en el movimiento obrero.

Es en estas condiciones que se ha dado el quiebre de la unidad entre fortalecimiento sindical y peronismo en el gobierno. Esto abre una serie de preguntas que remiten, directamente, a analizar las posibilidades de reconstrucción del "alma permanente" del peronismo, pero también (o sobre todo) a analizar las posibilidades (ya no sociológicas, sino estratégicas) de construcción de un "alma no peronista" de la actividad sindical. En 1973, en la presentación de un ya clásico Cuaderno de Pasado y Presente, los editores decían lo siguiente:

Vista las cosas desde este ángulo, cobra importancia la noción de estrategia sindical y se vuelve más fructífero plantearse la cuestión en estos términos: ¿Cómo forzar la inercia de las instituciones sindicales y formular una plataforma reivindicativa que unifique aquello que la división capitalista del trabajo divide y separa? (1973: IX)

Cuarenta años después esa pregunta resulta, quizás, más actual que entonces. La profunda precarización de la clase obrera heredada de los 90 es parte central de lo que "la inercia de las instituciones sindicales" mantiene y la política de las cúpulas garantiza. El sindicalismo de base surge sobre las bases de esa hiper precarización, pero despojado de las derrotas que el neoliberalismo significó y "bautizado" por el 2001. La pregunta por los modos en que esta nueva generación obrera puede reconstruir los lazos entre efectivos y precarios, en negro y en blanco, sindicalizados y no sindicalizados, e incluso, ocupados y desocupados, es la pregunta central para debatir la estrategia política (ya no sindical) de la izquierda clasista hacia los sindicatos en la actualidad. 


\section{Referencias}

AA.VV. (2007), Experiencias subterráneas. Trabajo, organización gremial e ideas politicas de los trabajadores del subte, Buenos Aires: Ediciones IPS.

Anino, P. (2008), “Síntomas de agotamiento del 'modelo’ K. ¿Del círculo virtuoso al círculo vicioso?”, en I Jornadas Internacionales de Investigación y Debate Político (VII Jornadas de Investigación Histórico Social), octubre, Buenos Aires.

Aizicson, F. (2009), Zanón. Una experiencia de lucha obrera, Herramienta Ediciones, Buenos Aires.

Bach, P. (2008), "El salario relativo en la Argentina de la devaluación", en Lucha de clases, revista marxista de teoría y politica $\mathrm{N}^{\circ} 8$, junio, Ediciones IPS, Buenos Aires.

Basualdo, E. (2008), "La distribución del ingreso en Argentina y sus condicionantes estructurales", en Derechos humanos en Argentina, informe anual CELS, Buenos Aires.

Cambiasso, M. (2011), "Hegemonía empresarial y estrategias de control laboral en el sector de la alimentación: el caso de Kraft-Terrabusi", en $2^{\circ}$ Congreso Internacional de Relaciones del Trabajo de la Universidad de Buenos Aires, 8 al 11 de noviembre 2011, Buenos Aires.

Campos, J. y L. Campos (2010), “Acerca de la persistencia de cláusulas de flexibilización laboral en los convenios colectivos de trabajo homologados en la postconvertibilidad", en Razón y Revolución, $\mathrm{N}^{\mathrm{0}} 20$, segundo semestre, Buenos Aires,

Castillo, C. y F. Rosso (2012), “Apuntes del PTS sobre la reconstrucción de un partido revolucionaria en Argentina", en Revista Estrategia Internacional, $\mathrm{N}^{\circ} 28$, año XXI, septiembre, Buenos Aires.

Castillo, C. y F. Lizarrague (2009), "Hacia el fin de un ciclo", en Lucha de Clases, $\mathrm{N}^{\circ} 8$, Ediciones IPS, junio, Buenos Aires.

Castillo, C. (2007), "Un recorrido por la lucha de clases en la Argentina reciente (1993-2006)", ponencia presentada en las IX Jornadas Interescuelas, septiembre, Tucumán.

Chitarroni, H. y E. Cimillo (2007), “¿Resurge el sujeto histórico? Cambios en el colectivo de trabajo: 1974-2006", en Lavboratorio/on line, año VIII, $\mathrm{N}^{\circ} 21$, verano, IIGG, Buenos Aires.

Collado A. y P. Varela (2008), "Hoy la fábrica es como un mundo nuevo, surgen jóvenes que se vuelven militantes de sus derechos", en Lucha de clases. Revista de Teoría y Politica, segunda época, $\mathrm{N}^{\circ} 8$, junio.

Cuadernos de Pasado y Presente (1973), "Presentación" en Economía y Politica en la Acción Sindical, PyP, Buenos Aires.

Duhalde, S. (2011), "Surgimiento de un nuevo modelo de sindicalismo en la Argentina: sus principales características”, Ensemble, revista electrónica de la Casa Argentina en París, Francia.

Etchemendy, S. (2012), "El sindicalismo argentino en la era pos-liberal 
(2003-2011)”, en Malamud y De Luca (coord.), La politica en tiempos de los Kirchner, Eudeba, Buenos Aires.

Etchemendy, S. y R.B. Collier (2007), "Down but not out: Union resurgence and segmented neocorporatism in Argentina (2003-2007)", en Politics and Society, vol. 35, $\mathrm{N}^{\circ} 3$, septiembre.

Eskenazi, M. (2011), "Acumulación de capital y conflictividad laboral en Argentina, 2002-2009: ejercicio de periodización e hipótesis de trabajo", ponencia en el XXVIII Congreso de la Asociación Latinoamericana de Sociología (ALAS), 6 al 10 de septiembre, Recife, Brasil.

Guevara, S. (2012), "Reactivación de la movilización obrera en la industria terminal automotriz (2004-2011). Recuperación parcial del salario con persistencia en la flexibilización laboral", en Trabajo y Sociedad, $\mathrm{N}^{\circ} 19$, invierno, Universidad Nacional de Santiago del Estero, Argentina.

Levitsky, S. (2005), La transformación del justicialismo. Del partido sindical al partido clientelista, 1983-1999, Siglo XXI, Buenos Aires.

Lindemboim, J. (2007), "Calidad del empleo y remuneraciones: el desafio actual", Realidad Económica N ${ }^{\circ} 228$, Buenos Aires.

Longo, J. (2011), "Precarización y conflictividad: resistencias y nuevas formas de organización en hipermercados", ponencia en el XXVIII Congreso de la Asociación Latinoamericana de Sociología (ALAS), 6 al 10 de septiembre, Recife, Brasil.

Lozano, C. et. al. (2008), "Sin mucho que festejar: radiografia actual del mercado laboral y las tendencias post-convertibilidad", informe del Instituto de Estudios y Formación, CTA, mayo, Buenos Aires.

Lozano y Raffo (2012), "El empleo en el período 2003-2011. Un recorrido por la post-convertibilidad", Instituto de Pensamiento y Políticas Públicas, mayo.

Marticorena, C. (2011), "Contrapuntos de la negociación colectiva en la industria manufacturera durante el periodo postconvertibilidad", $10^{\circ}$ Congreso Nacional de Estudios del Trabajo, ASET, Buenos Aires.

Meyer, L. y G. Gutiérrez (2005), "Las luchas obreras y los avances en la subjetividad", Revista Lucha de Clases, $N^{\circ} 5$, julio, Buenos Aires.

Montes Cató, J. y P. Ventrici (2011), "Renovación sindical en Argentina. Experiencias de revitalización democrática desde las bases", Latin American Perspectives, Estados Unidos.

Novick, M. (2006), “¿Emerge un nuevo modelo económico y social? El caso argentino 2003-2006”, Revista Latinoamericana de Estudios del Trabajo, Año $11, \mathrm{~N}^{\circ} 18$, pp. 53-78.

Palomino, H. y D. Trajtemberg (2006), "Una nueva dinámica de las relaciones laborales y la negociación colectiva en la Argentina”, Revista de Trabajo, año 2, No 3, MTEySS, Buenos Aires.

Palomino, H. (2008), "La instalación de un nuevo régimen de empleo en Argentina: de la precarización a la regulación", Revista Latinoamericana de Estudios del Trabajo, año 13, N 19, Caracas. 
Rojas, Diego (2011), ¿Quién mató a Mariano Ferreyra?, Editorial Norma, Buenos Aires.

Senén González, C., D. Trajtemberg y B. Medwid (2010), “Tendencias actuales de la afiliación sindical en Argentina: evidencias de una encuesta a empresas", Revista electrónica érudit, http://id.erudit.org/ iderudit/039526ar.

Varela, P. y D. Lotito (2009), "La lucha de Kraft-Terrabusi. Comisiones internas, izquierda clasista y 'vacancia' de representación sindical”, Revista Conflicto Social, Instituto Gino Germani, UBA, Buenos Aires.

Varela, P. (2009), "Repolitización fabril. El retorno de la politica de fábrica en la Argentina post-devaluación", en Giovani Alves y Claudia Figari (comps.), La precarización del trabajo en America Latina. Perspectivas del capitalismo global, Editorial Praxis, Brasil.

- (2008), "Rebeldía fabril: lucha y organización de los obreros de FATE", Lucha de Clases. Revista de teoría y politica marxista, $\mathrm{N}^{\circ} 8$, junio, Ediciones IPS, Buenos Aires.

Werner y Aguirre (2004), "El movimiento piquetero. Entre la lucha de clases y la institucionalización", Revista Estrategia Internacional, $\mathrm{N}^{\circ} 21$, septiembre, Buenos Aires.

Resumen: El nuevo protagonismo sindical en Argentina es un hecho ineludible. Eso ha abierto una serie de interpretaciones entre las que predomina la mirada "estatalista", que atribuye dicho protagonismo a la politica gubernamental de implantación de un "nuevo modelo de relaciones laborales" que revertiría el modelo neoliberal. En este trabajo presentaremos tres hipótesis que debaten con estas interpretaciones. La primera, que el fortalecimiento estatal de los sindicatos se enfrenta, desde el origen, a una contradicción constituyente del denominado "modelo kirchnerista": la recomposición social de la clase obrera sobre la reproducción de las condiciones de explotación de los 90. La segunda, que esta contradicción es la base objetiva sobre la que se desarrolla el fenómeno del sindicalismo de base, motivo por el cual su análisis es parte central del análisis de los sindicatos post-convertibilidad. La tercera, que la presencia de una nueva generación de trabajadores ("generación 2001") en combinación con la presencia de la izquierda radical (básicamente de tradición trotskista) en el movimiento obrero otorga a dicho sindicalismo de base características diferenciales respecto de otros períodos de la historia del movimiento obrero en nuestro país.

Palabras clave: sindicatos - precarización laboral - organización de base - izquierda

Abstract: Trade unions in Argentina have reached a new stage. That has led to a number of interpretations predominating an "statist" perspective attributing this role to the government policy of implementing a new model of labor relations that would reverse the neoliberal model. In this paper we present three 
scenarios discussed with these interpretations. The first, that strengthening unions faces to a contradiction constituent of the "Kirchnerist model": the social restructuring of the working class is based on the reproduction of the conditions of exploitation of 90 . The second, that this contradiction is the objective basis on which develops the emergence of grassroots unionism, and that's why its analysis is central to the analysis of post-convertibility unions. The third, that the presence of a new generation of workers ("2001 generation") in combination with the presence of the radical left (basically Trotskyist tradition) in the labor movement, give the grassroots unionism characteristics that distinguish them from other periods history of the labor movement in our country.

Key words: Unions - job insecurity and labor flexibility - grassroots unionism - left

Recepción: 21 de diciembre de 2012. Aprobación: 6 de febrero de 2013. 